\title{
Unusual presentation of submandibular lingual nerve sheath tumour as sublingual stone
}

\author{
Alexander J Straughan (D) ,' Christopher Badger (D) ,' Ramin Javan, ${ }^{2}$ Andrew Fuson, ${ }^{3}$ \\ Arjun S Joshi ${ }^{1}$
}

${ }^{1}$ Division of Otolaryngology - Head and Neck Surgery, Department of Surgery, George Washington University School of Medicine and Health Sciences, Washington, DC, USA

${ }^{2}$ Division of Neuroradiology, Department of Radiology, George Washington University School of Medicine and Health Sciences, Washington, DC, USA ${ }^{3}$ Department of Otolaryngology, University of Alabama School of Medicine, Birmingham, Alabama, USA

Correspondence to Mr Alexander I Straughan; AStraughan@gwmail.gwu.edu

Accepted 20 May 2020
Check for updates

(c) BMJ Publishing Group Limited 2020. No commercial re-use. See rights and permissions. Published by BMJ.

To cite: Straughan AJ, Badger $C$, Javan $R$, et al. BMJ Case Rep 2020;13:e233759. doi:10.1136/bcr-2019233759

\section{SUMMARY}

A 60-year-old woman was referred to the otolaryngologist for 18 months of left-sided tongue pain and taste changes. Surgeon-performed ultrasound of the submandibular region revealed a hyperechoic mass. Wharton's duct was dilated proximally and the submandibular gland demonstrated normal vascularity. While these findings were highly suspicious for submandibular gland sialolith, an in-office attempt at sialolithotomy suggested an alternate process or mass. After imaging failed to further elucidate an aetiology, surgical exploration revealed a well-circumscribed submandibular mass associated with the lingual nerve. The mass was removed en-bloc and pathology revealed a schwannoma of the lingual nerve.

\section{BACKGROUND}

The phrase 'When you hear hoofbeats behind you, don't expect to see a zebra' is a commonly used axiom in medical education to encourage clinicians to consider the simplest explanation for a medical diagnosis. ${ }^{1}$ While epidemiology and disease prevalence in patient populations are important factors in establishing clinical diagnoses, some patients remind us that the rare 'zebras' are worth consideration in a differential diagnosis. This report describes a patient presenting with a lingual mass suspected to be a submandibular gland sialolith. However, on surgical excision and pathological investigation the mass was determined to be a neurofibroma. These solitary tumours are rare, with only $6.5 \%$ being found within the oral cavity. ${ }^{2}$ While typically benign, they carry the potential for metastasis and should be excised surgically. ${ }^{3}$

Neurofibromas are benign tumours of peripheral nerve origin which typically present as a sporadic solitary lesion or as part of a predisposing genetic syndrome such as neurofibromatosis type I (von Ricklinghausen's disease) or multiple endocrine neoplasia type III; such conditions often present as multiple neurofibromas along with other manifestations of these disorders. ${ }^{3}$ Solitary neurofibromas are among the most common neural tumours; however, their appearance in the oral cavity remains rare. ${ }^{4}$ While neurofibromas most commonly present in the skin, $25 \%$ occur in the head and neck region and as previously stated $6.5 \%$ in the oral cavity. ${ }^{2}$ Neurofibromas of the oral cavity typically present as small, sessile lesions. Within the oral cavity, the most commonly affected sites are the lip, tongue and areas innervated by the mental nerve. Their smooth surface and slow growth can make them challenging to diagnose early in tumour development. ${ }^{5}$

\section{CASE PRESENTATION}

A 60-year-old woman with no significant medical history was referred to our academic otolaryngology clinic with left-sided glossodynia and dysgeusia. She had presented 18 months earlier to a dentist with similar pain. Prior head and neck CT and MRI were unrevealing. However, given the neurogenic character of the patient's glossodynia the patient was started on gabapentin for pain control.

On examination she was normotensive with a blood pressure of $111 / 62 \mathrm{~mm} \mathrm{Hg}$, heart rate of 54 bpm. Head and neck examination demonstrated a tender mucosal swelling in the left floor of mouth measuring $4 \mathrm{~mm}$ in diameter without palpable lymphadenopathy. General examination was otherwise normal.

\section{INVESTIGATIONS}

Initial investigation of the patient's mass began with MRI of the brain to investigate possible trigeminal neuralgia and other neuropathic pain sources. No

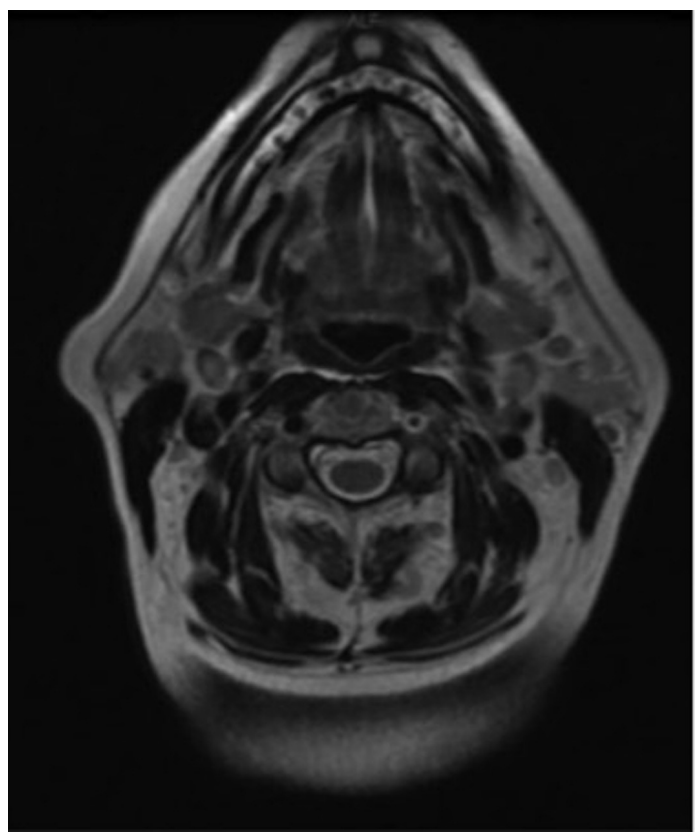

Figure 1 MRI study. 


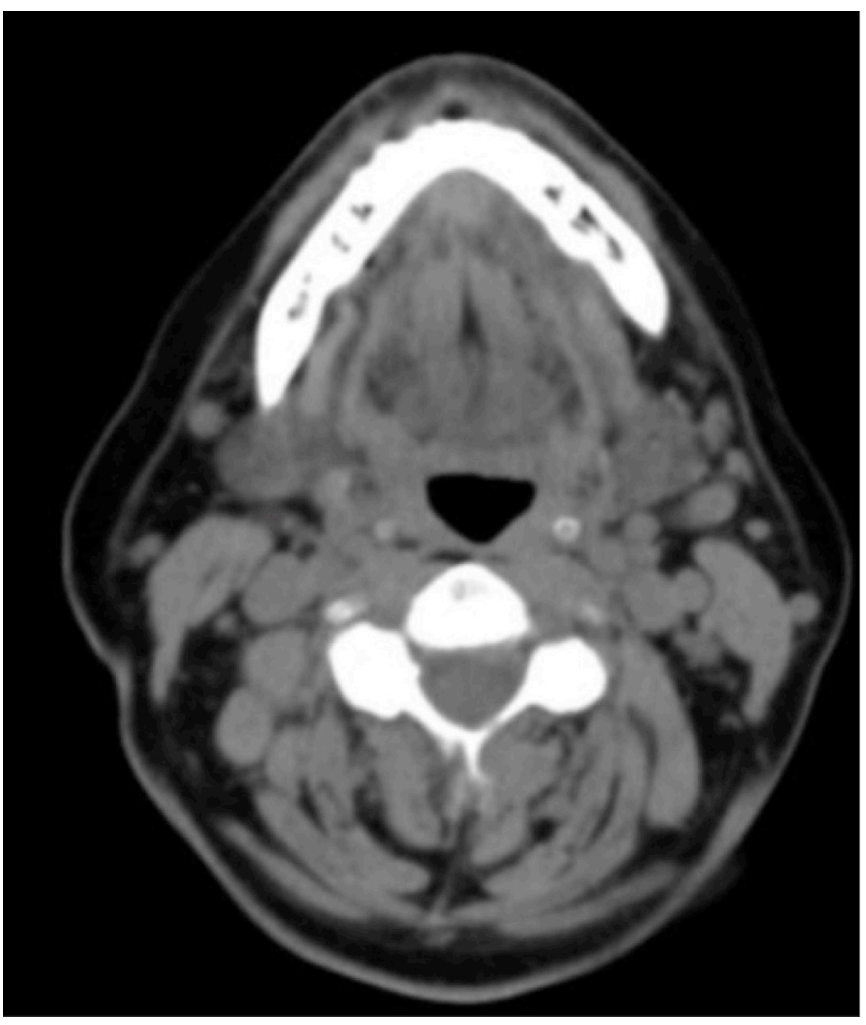

Figure 2 CT study.

focal abnormalities were shown which might account for her glossodynia (figure 1).

On referral to our clinic, an academic otolaryngology practice associated with a tertiary medical centre, the patient underwent surgeon-performed ultrasonography of the submandibular region which revealed a $5 \mathrm{~mm}$ hyperechoic submandibular mass. Unfortunately, these images were not recorded. Wharton's duct was observed to be dilated proximally with normal vascularity of the submandibular gland. These findings were interpreted as consistent with a sialolith of the left submandibular gland located in Wharton's duct. In accordance with this tentative diagnosis, the patient was consented and scheduled for in-office sialolithotomy. In-office excision of the presumed sialolith was attempted by an experienced head and neck surgeon, though quickly

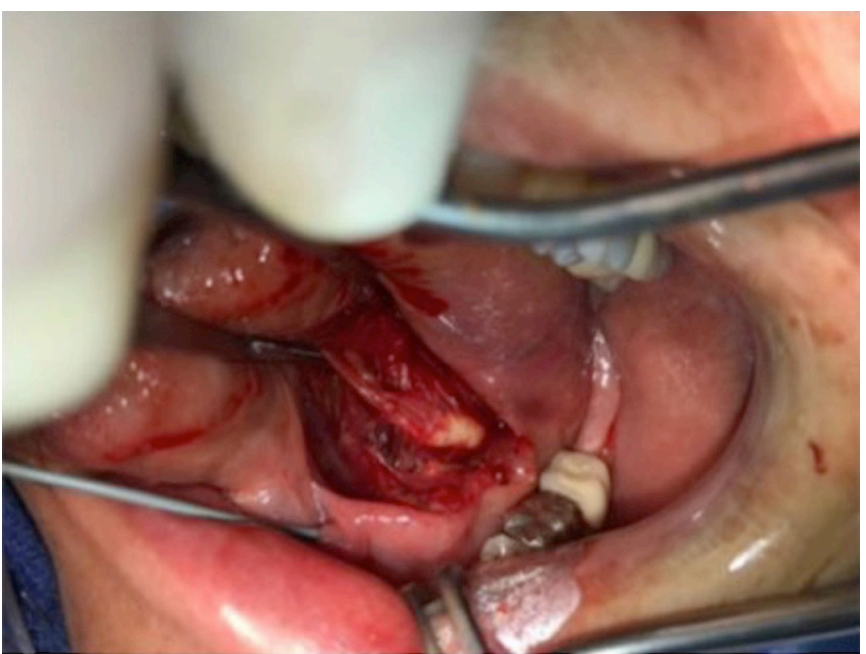

Figure 3 Intraoperative view of tumour.

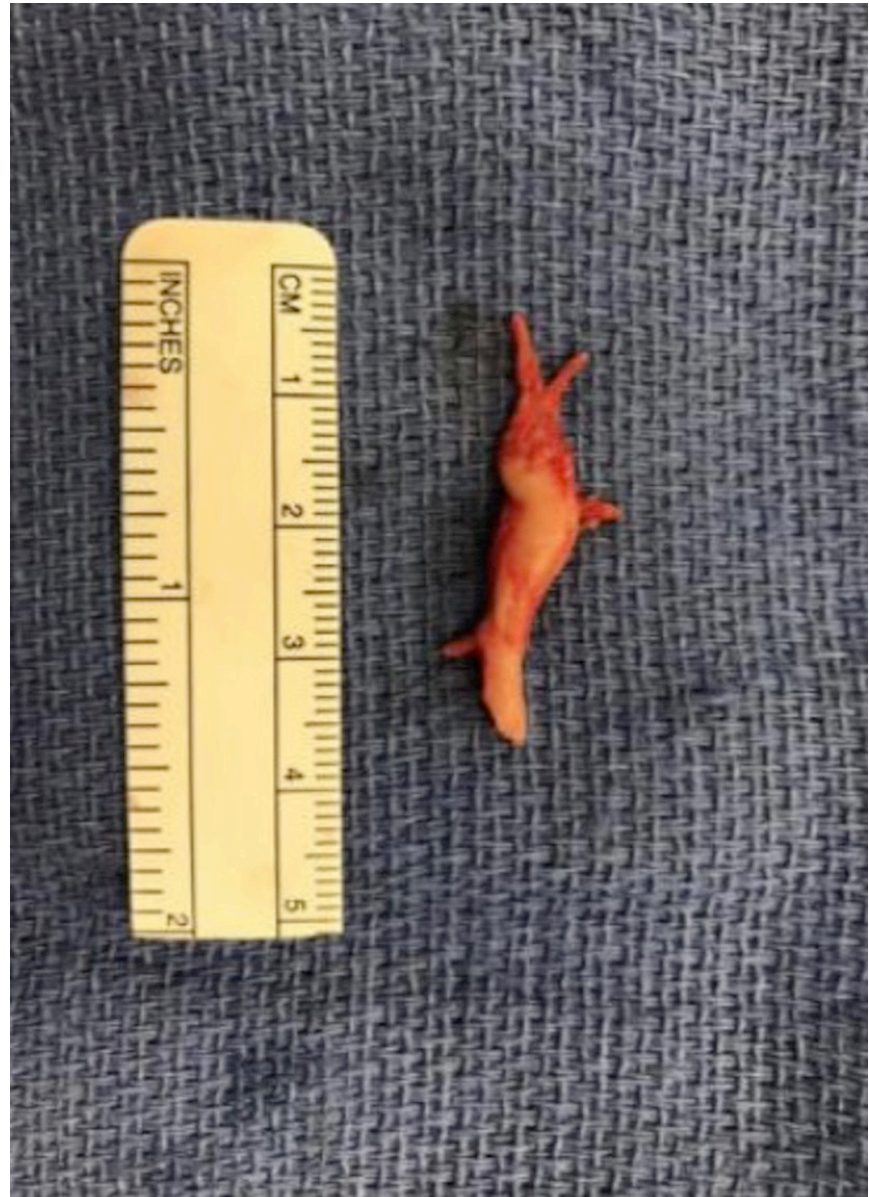

Figure 4 Gross tumour specimen.

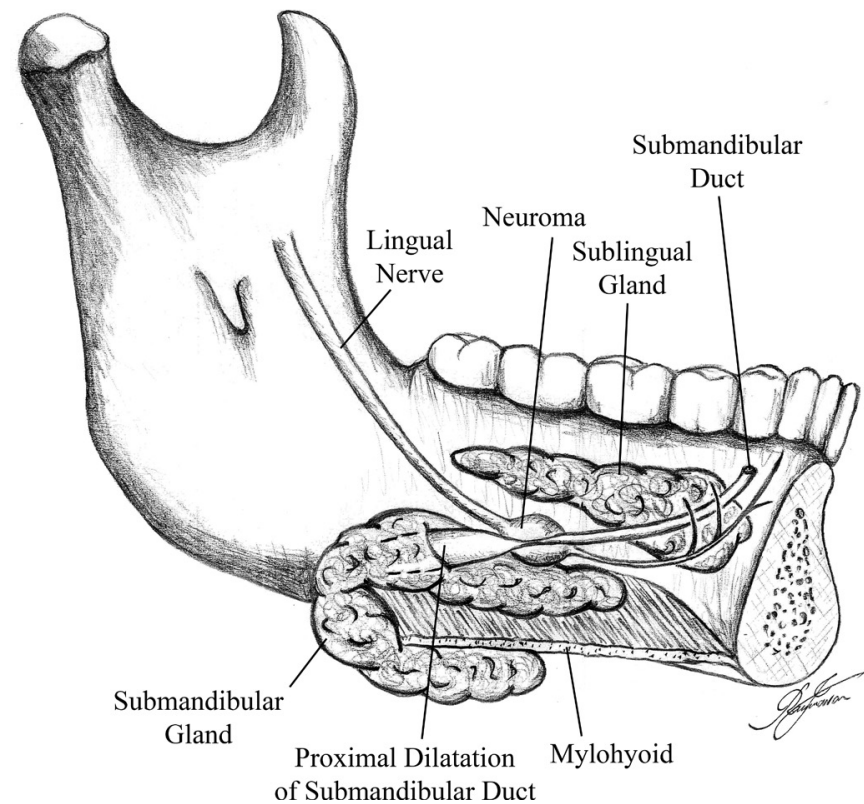

Figure 5 Artist rendering of patient anatomy. Illustration courtesy of Dr Ramin Javan, MD, Associate Professor of Radiology at George Washington School of Medicine and Health Sciences. 
aborted when the patient reported a sharp neurogenic pain of the anterior tongue despite local anaesthesia to the lingual nerve.

Previous MRI failed to identify a definitive aetiology, neuropathic or otherwise. Due to a persistently high-suspicion for sialolithiasis or other mass, a CT scan was performed (figure 2). Again, no definitive mass was identified; however, an asymmetrically prominent possible left facial vein in the submandibular region was noted. Symmetric submandibular glands without evidence of sialolithiasis or inflammatory changes were observed.

\section{TREATMENT}

The patient and surgeon agreed that operative exploration and excision was the most appropriate next step. Operative consent was obtained, and the patient was properly anaesthetised and prepped for surgery. A self-retaining Weitlaner retractor was applied for oral exposure. A sweetheart retractor was used to retract the tongue and expose the left floor of mouth. Submucosal injection with 1\% lidocaine and epinephrine was performed over the area of interest. The mass in the floor of mouth was easily palpable.

At that point the left submandibular papilla was identified and a 0.015 -inch guidewire was inserted into the duct. A five French salivary ductal dilator was then inserted over the guidewire into the submandibular ductal system and left in place. \#15 scalpel blade was used to make a mucosal incision only. The lingual nerve was identified on the genioglossus muscle after medial elevation of the submucosal flap. This was dissected more proximally and the mass of interest was clearly identified (figure 3). It appeared to be an intramural fusiform mass closely associated with the lingual nerve. Surgical clips were applied to the proximal and distal aspects of the lingual nerve and then divided (figure 4). The mass was then sent off to pathology for further analysis.

\section{OUTCOME AND FOLLOW-UP}

Pathology revealed bundles of normal nerve fascicles with abnormally thickened areas. These enlarged areas were well defined with a slight nodular architecture but not encapsulated. They were composed of sheets of large, monotonous, plump cells with distinct borders, abundant eosinophilic and granular cytoplasm and eccentrically placed nuclei. Periodic acid-Schiff (PAS) histochemical staining highlighted numerous eosinophilic cytoplasmic granules. Mitotic figures were not seen and there was no evidence of necrosis. Immunohistochemistry of the plump cells were strongly immunoreactive for S100 and CD68. Neurofilament protein and epithelial membrane antigen (EMA) were negative in the tumour and highlight only axons and perineurium. This picture is consistent with a neurofibroma.

One month after the lingual neuroma resection the patient's glossodynia was markedly improved without further pain or discomfort. The patient experienced numbness in a left lingual nerve distribution as expected with lingual nerve resection. Two years later the patient continues to deny glossodynia, but continues to experience residual numbness with dysgeusia.

\section{DISCUSSION}

Radiographic evidence of the salivary duct system dilatation should prompt suspicion of obstructive disorders and diseases, including sialolithiasis and salivary duct stenosis. Additionally, a salivary colic syndrome of postprandial pain in the gland is often seen. ${ }^{6}$ However, alternative processes should be considered, especially in the absence of classic salivary colic symptoms and presence of atypical symptoms such as neuropathic pain-as in our patient. The ductal dilatation in our patient was likely secondary to compression of the duct externally from the lingual nerve mass. As the lingual nerve is intimately associated with the submandibular duct, masses associated with the lingual nerve can plausibly compress on the duct (figure 5), and should be considered when ductal dilatation is observed. Although known to suffer from neurofibromatosis, the patient described in Wang et al similarly presented with a lingual-nerve-associated neurofibroma. ${ }^{7}$ However, no neuropathic pain was noted, and ductal dilatation was likely not explored.

Since their classification, few cases of solitary floor-of-mouth neurofibromas have been reported. ${ }^{8-12}$ According to these reports and our own patient, such tumours are heterogeneous on radiographic and MRI. A recently reported case of a solitary

\section{Patient's perspective}

My experience started with my tongue stinging. It was not only when something touched my tongue, but I noticed it would sting if I pressed on my neck or chin, too. At first I went to my dentist about the pain. She had no clue what to do. After that, I saw many specialists trying to understand what was going on. First, I saw an oral surgeon who did some bloodwork and tests, but with no success. Then I was sent to a neurologist, and of course I went through a brain scan and nothing was found. Nobody had any idea what was going on. We tried gabapentin for a while, but as worked picked up I found the sleepiness the medication caused to make concentration and working more difficult. And it didn't help; the only thing gabapentin did was help me sleep!

All of this was a 2-year process. In the meantime, my pain was getting worse and worse. It felt like a red-hot poker was being placed through my tongue. It was a constant, severe pain. At times, it would get worse-a shooting pain that would take my breath away and make me feel like crying. Beyond the pain, my taste buds were off. I had a very metallic taste in my mouth, like there was always blood or some metal in my mouth. I love my food, and kept trying different things to overcome this metallic taste and satisfy or fix my appetite. I drank a lot of water, which soothed the pain in my mind.

With luck, I ran into an otolaryngologist I knew through work. I asked if he had any suggestions, and he offered to look at my tongue. Personally, I hadn't thought to consider an ear, nose and throat doctor for my problem. When I saw him, he finally put together something was going on with the nerve. He told me there's a specialist he'd like me to see at his institution. This is when I eventually met the team. They thought it might have been a salivary gland stone. At this point, as the doctor tried to take out the stone in the office, but we could both tell something was wrong as I kept cringing from the pain. Even as he pressed down around my mouth or along my jaw I could feel the pain sharply, through the numbing medicine.

After my operation in which they found the nerve tumor, my pain relief was immediate. The difference was huge. It still feels somewhat numb and every once in a while, it still has a tingling sensation-like a dentist's numbing medication wearing off. Everybody at the institution was very helpful, and I appreciate their work in alleviating my pain. Additionally, my local otolaryngologist and other doctors were extremely supportive and helpful. Without them I could still be in pain.

It was a miserable and depressing 2 years, because the pain was chronic, always present, and with no relief. If at any time my story helps doctors diagnose it quicker so other patients don't have to go through the same pain, that would be wonderful. 


\section{Learning points}

- A firm understanding of head and neck anatomy should help guide the differential for a floor of mouth mass, which should include lingual neurofibroma.

- A hyperechoic mass in the floor of mouth with ultrasonographic evidence of submandibular duct obstruction does not always indicate sialolith or ductal stenosis, external and lingual nerve-associated masses such as neurofibroma should be considered in differential.

- Patient history may provide a clue to aetiologies involving the lingual nerve. Neuropathic pain of the tongue rather than salivary colic is suggestive of the diagnosis.

neurofibroma in the floor of mouth ${ }^{8}$ describes gross swelling and a well-defined mass $(18 \times 30 \times 35 \mathrm{~mm})$ on MRI, unlike our patient's lack of significant gross swelling or significant radiological findings (figures 1 and 2, ultrasound investigation findings). Submandibular gland ductal dilation was observed both cases. Unlike other reported cases, which generally have not been associated with direct pain $^{8-10}$ (with the exception of the patient described by Chao et al to have a foreign body sensation ${ }^{11}$ ), this patient experienced severe, neuropathic lingual pain, likely secondary to compression of the lingual nerve.

Contributors Supervised by ASJ. Patient was under the care of ASJ. Report was written by AJS, CB, RJ, AF, and ASJ.

Funding The authors have not declared a specific grant for this research from any funding agency in the public, commercial or not-for-profit sectors.
Competing interests None declared.

Patient consent for publication Obtained.

Provenance and peer review Not commissioned; externally peer reviewed.

\section{ORCID iDs}

Alexander J Straughan http://orcid.org/0000-0001-9967-546X

Christopher Badger http://orcid.org/0000-0002-3714-0272

\section{REFERENCES}

1 Sotos JG. Zebra Cards: An Aid to Obscure Diagnoses. In: Vernon book systems. Mt. Vernon, VA: Mt. Vernon Book Systems, 2006.

2 Shack RB, Reilley AF, Lynch JB. Neurofibromas of the head and neck. South Med J 1985;78:801-4.

3 Ferner RE, Gutmann DH. Neurofibromatosis type 1 (NF1): diagnosis and management. Handb Clin Neurol 2013:115:939-55.

4 Depprich R, Singh DD, Reinecke P, et al. Head \& Face Medicine Solitarysubmucous neurofibroma of the mandible: review of the literature and report of a rare case. Head Face Med 2009;4:5-24

5 Zachariades N, Mezitis M, Vairaktaris E, et al. Benign neurogenic tumors of the oral cavity. Int J Oral Maxillofac Surg 1987;16:70-6.

6 Buckenham T. Salivary duct intervention. Semin Intervent Radiol 2004;21:143-8.

7 Wang H-M, Hsu Y-C, Lee K-W, et al. Neurofibroma of the lingual nerve: a case report. Kaohsiung J Med Sci 2006;22:461-4.

8 Broly E, Lefevre B, Zachar D, et al. Solitary neurofibroma of the floor of the mouth : rare localization at lingual nerve with intraoral excision. BMC Oral Health 2019:1-8.

9 Maruyama M, Fushiki H, Watanabe Y. Solitary neurofibroma of the floor of the mouth: a case report. Case Rep Otolaryngol 2011;2011:967896.

10 Srivathsa SH. Solitary neurofibroma of the floor of the mouth. Int J Clin Correl 2017; 1:20-2.

11 Chao Y-T, Li W-Y, Chu P-Y. Postradiation tumor in the floor of mouth. JAMA Otolaryngol Head Neck Surg 2015;141:663-4.

12 Al-Omran M, Al-Khamis A, Malik A. Solitary neurofibroma of the floor of mouth. Neurosciences 2006;1:53-5.

Copyright 2020 BMJ Publishing Group. All rights reserved. For permission to reuse any of this content visit

https://www.bmj.com/company/products-services/rights-and-licensing/permissions/

BMJ Case Report Fellows may re-use this article for personal use and teaching without any further permission.

Become a Fellow of BMJ Case Reports today and you can:

- Submit as many cases as you like

- Enjoy fast sympathetic peer review and rapid publication of accepted articles

- Access all the published articles

- Re-use any of the published material for personal use and teaching without further permission

Customer Service

If you have any further queries about your subscription, please contact our customer services team on +44 (0) 2071111105 or via email at support@bmj.com.

Visit casereports.bmj.com for more articles like this and to become a Fellow 